\title{
Modeling Tetra-n-butyl ammonium halides aqueous solutions with the electrolyte cubic plus association equation of state
}

Sun, Li; Liang, Xiaodong; Solms, Nicolas von; Kontogeorgis, Georgios M.

Published in:

Fluid Phase Equilibria

Link to article, DOI:

https://doi.org/10.1016/j.fluid.2018.12.033

Publication date:

2019

Document Version

Peer reviewed version

Link back to DTU Orbit

Citation (APA):

Sun, L., Liang, X., Solms, N. V., \& Kontogeorgis, G. M. (2019). Modeling Tetra-n-butyl ammonium halides aqueous solutions with the electrolyte cubic plus association equation of state. Fluid Phase Equilibria, 486, 37 47. https://doi.org/10.1016/j.fluid.2018.12.033

\section{General rights}

Copyright and moral rights for the publications made accessible in the public portal are retained by the authors and/or other copyright owners and it is a condition of accessing publications that users recognise and abide by the legal requirements associated with these rights.

- Users may download and print one copy of any publication from the public portal for the purpose of private study or research.

- You may not further distribute the material or use it for any profit-making activity or commercial gain

- You may freely distribute the URL identifying the publication in the public portal 


\section{Accepted Manuscript}

Modeling Tetra-n-butyl ammonium halides aqueous solutions with the electrolyte CPA equation of state

Li Sun, Xiaodong Liang, Nicolas von Solms, Georgios M. Kontogeorgis

PII:

S0378-3812(18)30536-3

DOI:

https://doi.org/10.1016/j.fluid.2018.12.033

Reference: FLUID 12058

To appear in: Fluid Phase Equilibria

Received Date: 26 August 2018

Revised Date: 20 December 2018

Accepted Date: 24 December 2018

Please cite this article as: L. Sun, X. Liang, N. von Solms, G.M. Kontogeorgis, Modeling Tetra-n-butyl ammonium halides aqueous solutions with the electrolyte CPA equation of state, Fluid Phase Equilibria (2019), doi: https://doi.org/10.1016/j.fluid.2018.12.033.

This is a PDF file of an unedited manuscript that has been accepted for publication. As a service to our customers we are providing this early version of the manuscript. The manuscript will undergo copyediting, typesetting, and review of the resulting proof before it is published in its final form. Please note that during the production process errors may be discovered which could affect the content, and all legal disclaimers that apply to the journal pertain. 
Modeling Tetra-n-butyl Ammonium Halides Aqueous Solutions with the Electrolyte CPA Equation of State

Li Sun, Xiaodong Liang, Nicolas von Solms, Georgios M. Kontogeorgis*

Center for Energy Resources Engineering (CERE)

Department of Chemical and Biochemical Engineering

Technical University of Denmark (DTU)

Søltofts Plads, Building 229

2800 Kgs. Lyngby, Denmark

Keywords: e-CPA; TBAB; Semi-clathrate Hydrate; Relative Static Permittivity; Thermodynamic Properties 


\section{Abstract}

This work presents the thermodynamic modeling of the fluid phases of Tetra-n-butyl ammonium halides aqueous solutions with the electrolyte Cubic-Plus-Association (e-CPA) Equation of State (EOS). The adjustable model parameters are obtained by fitting the experimental data of mean ionic activity coefficients and osmotic coefficients. Several other thermodynamic properties of the aqueous solutions, such as relative static permittivity, liquid density and saturation pressure, are subsequently predicted by the eCPA EOS. The results of Tetra-n-butyl ammonium bromide aqueous solution show that the model can satisfactorily correlate the mean ionic activity coefficients and osmotic coefficients with the percentage average absolute deviations being $7.2 \%$ and $5.9 \%$. The model overpredicts the liquid density with a deviation of $9.2 \%$, while it can correlate the liquid density within $0.2 \%$ with a volume translation parameter. In order to have a more complete picture of the capabilities and limitations of the model, the consistencies of experimental data, parameter estimation approaches and the ion sizes are extensively analyzed and discussed. 


\section{Introduction}

Semi-clathrate hydrates $(\mathrm{SCH})$ have attracted attention in recent years, because of application possibilities such as gas separation, thermal storage, $\mathrm{CO}_{2}$ sequestration and $\mathrm{CH}_{4}$ transportation [1, 2, 3]. In 1940, Fowler and coworkers [4] discovered that the addition of some quaternary ammonium salts, such as Tetra-n-butyl ammonium fluoride in water, could result in the formation of crystals at room temperature. McMullan and Jeffrey [5] used X-ray diffraction to report dimensions of the unit cells, hydration numbers, and crystal symmetry in 1959. Jeffrey and coworkers [6] studied the structure of these crystals using crystallographic and X-ray structural analysis, and they proposed to call them semiclathrates in 1969. In the structure of $\mathrm{SCH}$, the anions of salts coupled with water molecules build a clathrate framework (formed by hydrophilic beads), and the cation is embedded in framework cavities (formed by hydrophobic beads), while the small guest gas molecules could be contained in empty pentagonal dodecahedron cages. This special structure makes $\mathrm{SCH}$ more stable than usual hydrates. Since there is a wide range of anions and cations that can compose semi-clathrates, many different crystalline structures can be formed. Dyadin and Udachin [7] provided comparative analysis of structures and characteristics between $\mathrm{SCH}$ and normal gas hydrates. Dyadin et al. [8] discussed the structural stability of $\mathrm{SCH}$ with respect to their stoichiometry. Nowadays, Tetra-n-butyl ammonium halides (in short, TBAX, with $\mathrm{X}$ being bromide: $\mathrm{B}$, chloride: $\mathrm{C}$, fluoride: $\mathrm{F}$, nitrate: $\mathrm{NO}_{3}$ etc.) and Tetra-n-butyl phosphonium halides (in short, TBPX) receive most attention as $\mathrm{SCH}$ additives $[7,8,9,10]$.

The fluid phase modeling is an important step for the thermodynamic modeling of TBAX containing SCH systems. Different approaches have been proposed for TBAX aqueous solutions. One typical approach is the so-called $\varphi-\varphi$ approach, which uses an electrolyte equation of state (EOS) for all phases. Paricaud [11] used the statistical associating fluid theory with variable range for electrolytes (SAFT-VRE) to describe the fluid phases. Following Paricaud's approach, Fukumoto et al. [12, 13, 14] adjusted the temperature dependency parameter in the SAFT-VRE EOS by using solid-liquid equilibrium data of 
salt-water binary systems, and applied the approach to TBAB, TBAC, TBAF, TBPB, and $\mathrm{TBANO}_{3} \mathrm{SCH}$ systems. Babu et al. [15] re-adjusted the depth of the square-well cell potential, enthalpic and melting point parameters, and applied the approach to $\mathrm{TBANO}_{3}$ system. The SAFT-VRE EOS is shown to give a satisfactory agreement with experimental data for the mean ionic activity coefficients and osmotic coefficients of TBAX aqueous solutions [11, 12]. For other TBAX systems, Fukumoto et al. [12] stated that good description of mean ionic activity coefficients and osmotic coefficients of electrolyte solution can be obtained by using SAFT-VRE. Ma et al. [16] applied the Modified PatelTeja (MPT) EOS [17] to the fluid phase equilibrium calculations for the TBAB aqueous solution and TBAF aqueous solution. The MPT EOS uses a Debye-Hückel term for the electrostatic contributions, while the authors [16] give few details of fluid modeling performance for TBAX related systems.

Another typical approach is the so-called $\varphi-\gamma$ approach, which uses a non-electrolyte EOS for the vapor phase and an electrolyte activity coefficient model for the liquid phase. The electrolyte non-random two-liquid (e-NRTL) model proposed by Chen et al. [18] is a common model for the activity coefficient in this approach. e-NRTL performs very well in modeling activity coefficients of quaternary ammonium salts in water at $298.15 \mathrm{~K}$ [19]. Based on the mean spherical approximation for aqueous electrolytes (MSA-NRTL) model, AMSA-NRTL [20] takes the ionic hydration and association into account. Kwaterski and Herri [21] used the Soave-Redlich-Kwong (SRK) EOS plus e-NRTL for the TBAB aqueous solution. Verrett et al. [22] used the Trebble-Bishnoi (TB) EOS plus e-NRTL for the TBAB aqueous solution, Shi and Liang [23] applied the Peng-Robinson (PR) EOS plus e-NRTL for TBAB, TBAC, and TBAF aqueous solutions, Najibi et al. [24] utilized the PR EOS plus AMSA-NRTL for TBAB aqueous solutions. Both e-NRTL and AMSA-NRTL provide good agreement with experimental data of mean ionic activity coefficients (the performance can be seen in the discussion section). Eslamimanesh et al. [25] used the PR EOS for the vapor phase, plus NRTL for non-electrolyte compounds in the liquid phase, and they used a correlation based on the experimental data for the mean ionic activity 
coefficients of the electrolyte part. These authors did not investigate the predictive ability of the model for TBAB related fluid systems. Other researchers [26, 27, 28] applied nonelectrolyte EOS plus empirical correlations for water activity.

It is of interest to investigate a new modeling approach, and the predictive capability and flexibility of the approach over a wide range of properties. In this work, the electrolyte Cubic-Plus-Association (e-CPA) EOS proposed by Maribo-Mogensen et al. [29, 30] is used. The adjustable parameters will be obtained by fitting the mean ionic activity coefficients and osmotic coefficients, and other thermodynamic properties will be predicted by e-CPA. The parameter estimation procedure and modeling approaches will be analyzed and discussed.

The rest of the paper is organized as follows: firstly, thermodynamic properties of TBAX aqueous solutions will be shortly introduced. Then, e-CPA will be presented, and the parameter estimation results of modeling will be proposed. Finally, analysis of the parameter estimation will be presented, followed by our conclusions.

\section{Thermodynamic Properties of TBAX Aqueous Solutions}

TBAX are common additives for $\mathrm{SCH}$, and TBAX aqueous solutions have been extensively studied because of potential industrial applications, such as intermediate reactants and as phase transfer catalysts [11]. Tetra-n-butyl ammonium cation $\left(\mathrm{TBA}^{+}\right)$is a hydrophobic organic cation, with a molecular formula $\left.\left[\mathrm{CH}_{3}\left(\mathrm{CH}_{2}\right)_{3}\right)\right]_{4} \mathrm{~N}^{+}$.

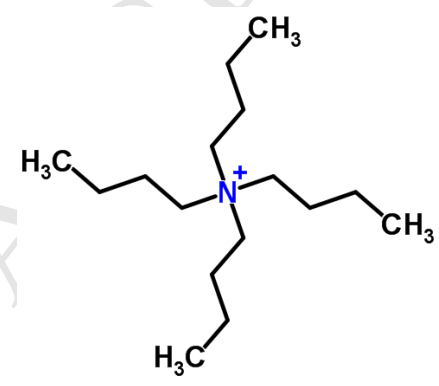

(a) $2 \mathrm{D}$

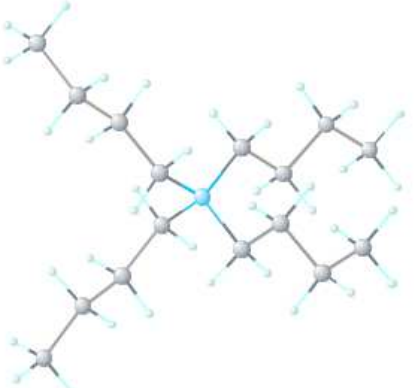

(b) 3D

Figure 1. Structural formula of $\mathrm{TBA}^{+}[31]$. 
It can be seen from Figure 1 that $\mathrm{TBA}^{+}$has four long and soft hydrophobic alkyl side chains, and the positive charge, which comes from the center nitrogen atom, is sterically hindered by the alkyl substituents. Thermodynamic properties of the TBAX aqueous solutions are influenced by the interactions that occur between the hydrophobic alkyl groups of the ions and the water molecules [32]. Table 1 summarize experimental studies of mean ionic activity coefficients and osmotic coefficients for TBAX aqueous solutions at atmospheric pressure.

Table 1. Experimental studies of mean ionic activity coefficients and osmotic coefficients for TBAX aqueous solutions at atmospheric pressure

\begin{tabular}{lllll}
\hline TBAX & Molality [mol/kg water] & Temperature $[\mathrm{K}]$ & $\mathrm{N}^{*}$ & Ref. \\
\hline \multirow{2}{*}{ TBAB } & $0.1 \sim 27$ & 298.15 & 38 & {$[33]$} \\
& $0.0912 \sim 1.0060$ & 298.15 & 10 & {$[34]$} \\
& $0.1 \sim 9.5$ & $298.15,373.15,423.15$ & $27^{+}$ & {$[35]$} \\
\hline TBAC & $0.1 \sim 15$ & 298.15 & 32 & {$[33]$} \\
TBAF & $0.1 \sim 1.6$ & 298.15 & 13 & {$[36]$} \\
\hline
\end{tabular}

$\mathrm{N}$ represents the number of data points. ${ }^{+}$The authors gave the changes in osmotic coefficients and in activity coefficients.

The mean ionic activity coefficients and osmotic coefficients are important for electrolyte solutions. It can be seen from Figure 2 that these two properties of TBAX aqueous solutions are complex functions of molality. For the TBAB system, at low to medium salt concentration, both the mean ionic activity coefficients and osmotic coefficients decrease with increasing salt concentration. At higher salt concentration, both activity coefficients show a slight increase. For the TBAC system, at low molality, the values of mean ionic activity coefficients and osmotic coefficients first decrease, and then increase to reach maxima at around $2 \mathrm{~mol} / \mathrm{kg}$ water. After the maxima, the values first decrease, and then rise again. The mean ionic activity coefficients and osmotic coefficients of TBAF solution 
increase sharply with increasing salt concentration. Wen et al. [36] stated that the large values for these fluorides could be attributed to the 'structural repulsion': $\mathrm{F}^{-}$anion is small and may tend to immobilize water in a more or less radial pattern around it due to its specific size and surface charge density [36]. The $\mathrm{TBA}^{+}$is large and tends to enhance the 'cage-like' structure of water due to its hydrophobic properties. The cation and anion compete against each other to influence the structure of water in different ways.

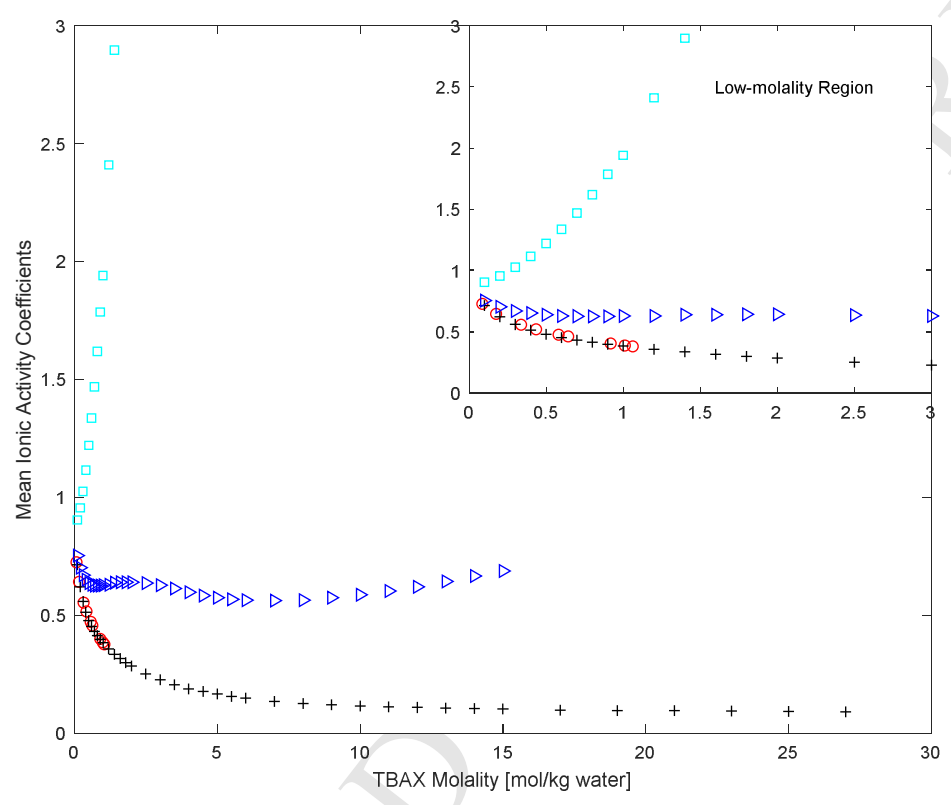

(a) Mean ionic activity coefficients.

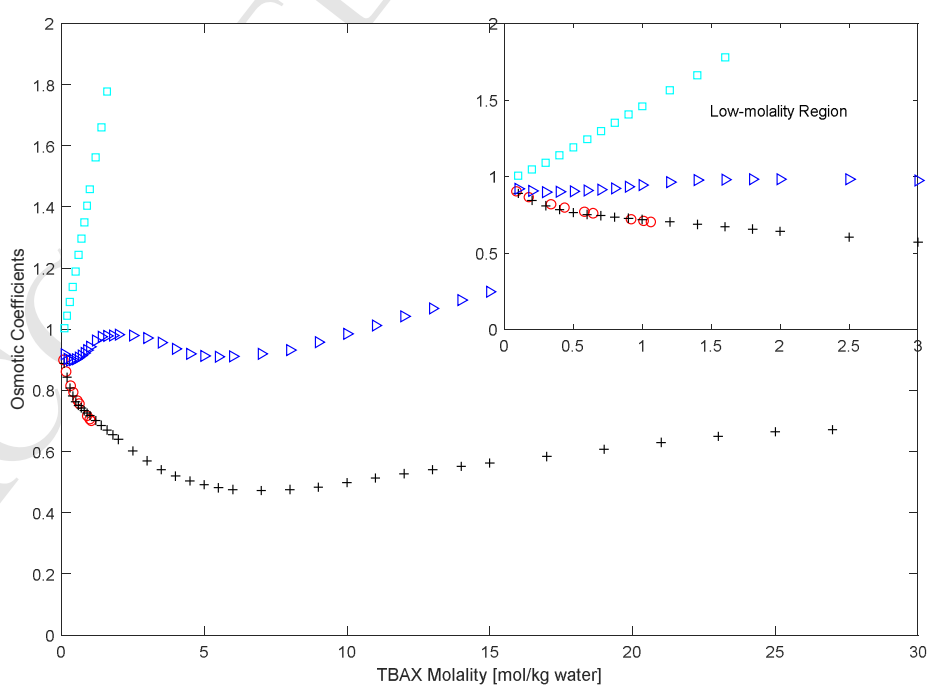

(b) Osmotic coefficients.

Figure 2. Experimental data of (a) mean ionic activity coefficients and (b) osmotic coefficients of TBAX aqueous solution at $298.15 \mathrm{~K}$. ०, TBAB aqueous solution (Amado 
and Blanco, 2005 [34]); +, TBAB aqueous solution (Lindenbaum and Boyd, 1964 [33]); , TBAC aqueous solution (Lindenbaum and Boyd, 1964 [33]); 口, TBAF aqueous solution (Wen et al., 1965 [36]).

Ion radius is a very important physical parameter in electrostatic calculations. Pauling [37] stated that there is no specified size which can be assigned to an ion, because of the indefinite extent of the electron distribution function. Pauling [37] also pointed that the apparent ionic radius will depend on the physical properties.

Different type of ion sizes for $\mathrm{TBA}^{+}$are published. Pauling radius is calculated from the nuclear charge and the shielding constant based on Pauling rules. van der Waals radius is the radius of an imaginary hard sphere representing the distance of closest approach for another atom. Hard-sphere radius is calculated from the rigid sphere model. Hydrated radius is the radius of ion and closely bounded water molecules. Stokes radius (or hydrodynamic radius) is the radius of a hard sphere that diffuses at the same rate as the solute. McGowan radius is calculated from the McGowan characteristic volume, which is the actual volume of a mole when the molecules are not in motion. Table 2 summarizes some published ion size of $\mathrm{TBA}^{+}$, from which it can be seen that the radii of $\mathrm{TBA}^{+}$vary from $3.81 \AA$ to $4.94 \AA$, a difference (highest to lowest value) of $1.13 \AA$. The $\mathrm{TBA}^{+}$is a soft and irregular organic cation, and it is not entirely clear which radius approximately reflects the physics of the electrostatic interactions. For this reason, the effect of ion radius on the thermodynamic modeling will be investigated in this work.

Table 2. Summary of literature values proposed for the radius of $\mathrm{TBA}^{+}$

\begin{tabular}{ccc}
\hline Size Type & Ion Radius $r(\AA)$ & Reference \\
\hline Pauling crystal radius & 4.94 & {$[38]$} \\
\hline van der Waals radius & 3.87 & {$[39]$} \\
& 4.13 & {$[32,40]$} \\
\hline hard-sphere radius & 3.81 & {$[41]$} \\
\hline hydrated radius & 4.94 & {$[42]$} \\
\hline hydrodynamic radius & 3.84 & {$[43]$}
\end{tabular}




\section{The e-CPA EOS}

Maribo-Mogensen et al. [29, 30] extended the CPA EOS, proposed by Kontogeorgis et al. [46], to mixtures containing electrolytes. It includes the electrostatic contributions from the Debye-Hückel theory [47] (which accounts for the long-range interaction of the ions), and the Born equation [48] (which accounts for ion solvation).

In the e-CPA EOS, the residual Helmholtz energy is given by

$A^{r}=A^{S R K}+A^{A S S O C}+A^{D H}+A^{B o r n}$

In the right-hand side of Eq. (1), the first two terms are the contributions from CPA, and the remaining two contributions are from the Debye-Hückel theory [49] and Born equation [48], respectively.

The residual Helmholtz energy for the cubic Soave-Redlich-Kwong EOS [50] is calculated from

$A^{S R K}=n R T\left[-\ln \left(1-\frac{b}{v}\right)-\frac{a(T)}{b R T} \ln \left(1+\frac{b}{v}\right)\right]$

Where $n$ is the total number of moles, $T$ is the temperature, $R$ is the gas constant, $v$ is the molar volume, $b$ is the CPA co-volume parameter of the mixture, calculated from the pure component co-volume parameter $b_{i}$,

$b=\sum_{i} x_{i} b_{i}$

And $a(T)$ is the temperature dependent energy parameter of the mixture, obtained via the Huron-Vidal/NRTL (HV-NRTL) infinite pressure mixing rule [29, 51],

$\frac{a}{b}=\sum_{i} x_{i} \frac{a_{i}}{b_{i}}-\frac{g^{E, \infty}}{\ln 2}$

$\frac{g^{E, \infty}}{R T}=\sum_{i} x_{i} \frac{\sum_{j} x_{j} b_{j} \exp \left(-\alpha_{j i} \frac{\Delta U_{j i}}{R T}\right) \frac{\Delta U_{j i}}{R T}}{\sum_{j} x_{j} b_{j} \exp \left(-\alpha_{j i} \frac{\Delta U_{j i}}{R T}\right)}$ 
Where $x_{i}$ is the mole fractions of component $i$ (solvent, cation, anion), $g^{E, \infty}$ is the excess Gibbs energy at infinite pressure calculated with the NRTL equation, $\alpha_{j i}$ is the NRTL nonrandomness parameter, $\Delta U_{j i}$ is the change in interaction energy between like and unlike interactions $\left(\Delta U_{j i}=\Delta U_{i j}-\Delta U_{j j}\right)$, and the temperature dependent component specific parameter $a_{i}$ is given by

$a_{i}=a_{0 i}\left(1+c_{1 i}\left(1-\sqrt{T_{r i}}\right)\right)^{2}$

Where $T_{r i}$ is the reduced temperature of component $i$, defined as $T_{r i}=T / T_{c i}$, with $T_{c i}$ the critical temperature of component $i$. Therefore, $b_{i}, a_{0 i}$ and $c_{1 i}$ are adjustable pure component CPA parameters. In this work, the CPA reduced energy parameter $\Gamma_{i}=\mathrm{a}_{0 i} / R b_{i}$ is used.

It is worth pointing out that the HV-NRTL infinite pressure mixing rule has the flexibility to reduce to the classical one-fluid mixing rule if $\alpha_{j i}$ is set to zero and $\Delta U_{j i}$ is appropriately chosen. In order to apply the model over a wide range of temperature, a quadratic temperature dependence for the interaction parameter was proposed [29]

$\frac{\Delta U_{i j}}{R}=\frac{\Delta U_{i j}^{r e f}}{R}+\omega_{\Delta U_{i j}}\left[\left(1-\frac{T}{T_{\Delta U_{i j}}}\right)^{2}-\left(1-\frac{T_{r e f}}{T_{\Delta U_{i j}}}\right)^{2}\right]$

Where $T_{r e f}$ is the reference temperature and set to $298.15 \mathrm{~K}$, and $\Delta U_{i j}^{r e f}, \omega_{\Delta U_{i j}}$ and $T_{\Delta U_{i j}}$ are adjustable parameters.

The residual Helmholtz energy for association $A^{A S S O C}$ is similar to SAFT [52]: based on the formulation of Wertheim's association theory $[53,54,55,56]$ and can be found from the solution of the constrained optimization problem [57] given by

$A^{a s s o c}=R T\left[\sum_{i} n_{i} \sum_{A_{i}}\left(\ln X_{A_{i}}-\frac{1}{2} X_{A_{i}}+\frac{1}{2}\right)\right]$

$\frac{1}{X_{A_{i}}}=1+\sum_{j} \rho_{j} \sum_{B_{i}} X_{B_{j}} \Delta_{A_{i} B_{j}}$

In Eqs. (8) and (9), $X_{A_{i}}$ is the fraction of site A on component $i$ that is not bonded to any other site, $\rho_{j}$ is the density of component $j$, and $\Delta_{A_{i} B_{j}}$ is the association strength, which is 
calculated from

$\Delta_{A_{i} B_{j}}=g(\rho)\left[\exp \left(\frac{\varepsilon^{A_{i} B_{j}}}{k_{B} T}\right)-1\right] b_{i j} \beta^{A_{i} B_{j}}$

Where, the two association parameters are the association volume, $\beta^{A_{i} B_{j}}$, and the association energy, $\varepsilon^{A_{i} B_{j}}$, while $b_{i j}$ is given as $b_{i j}=\left(b_{i}+b_{j}\right) / 2$. The simplified radial distribution function $g(\rho)=(1-1.9 \eta)^{-1}$, and the packing fraction $\eta$ is equal to $b / 4 v$.

The contribution to the Helmholtz energy from ion-ion interactions is calculated from the Debye-Hückel theory [47], as shown in the following equation

$A^{D H}=-\frac{k_{B} T V}{4 \pi N_{A} \sum_{i} n_{i} z_{i}^{2}} \sum_{i} n_{i} z_{i}^{2} \chi_{i}$

Where, $V$ is the total volume, $n_{i}$ is the mole number of component $i, k_{B}$ is Boltzmann constant, $N_{A}$ is the Avogadro constant, $Z_{i}$ is the charge of component $i$, and the function $\chi_{i}$ is given by

$\chi_{i}=\frac{1}{d_{i}^{3}}\left[\ln \left(1+\kappa d_{i}\right)-\kappa d_{i}+\frac{1}{2}\left(\kappa d_{i}\right)^{2}\right]$

Where, $\kappa$ is the inverse Debye screening length, and $d_{i}$ is the hard-sphere diameter of the ion. Maribo-Mogensen et al. [29, 30] assumed that in the Eq. (12) the same value of the ion diameter as in the physical part of the EOS can be used.

Finally, the contribution of ion-solvation is from the Born equation $[48,58]$

$A^{\text {Born }}=\frac{N_{A} e^{2}}{8 \pi \varepsilon_{0}} \sum_{i} \frac{n_{i} z_{i}^{2}}{r_{B o r n, i}}\left(\frac{1}{\varepsilon_{r}}-1\right)$

Where, $r_{B o r n, i}$ is the radius of the Born cavity caused by the transfer from vacuum to the fluid phase, and $e$ is the elementary charge.

The relative static permittivity is of central importance in the thermodynamics of electrolyte solutions [59, 60]. In e-CPA, the model developed by Maribo-Mogensen [30, 61] for the relative static permittivity is used in both Debye-Hückel and Born terms. For more details, the reader is referred to the Support Information and Maribo-Mogensen et al. [30]. 


\section{Results and Discussion}

\subsection{Parameter Setting and Discussion}

As presented above, the framework of e-CPA is set up to account for each ion separately, and it is by nature ion specific. For a single salt/single solvent solution, there are in principle six pure component parameters (five CPA parameters and one Born term parameter) and twelve interaction parameters for the standard e-CPA EOS (as shown in Eqs. (4) and (5), the HV-NRTL mixing rule gives the possibility of having four additional adjustable parameters per interaction, which for a single salt in a solvent will be three interactions: cation-anion, cation-solvent, and anion-solvent). In order to minimize the number of parameters, a series of assumptions are made [29, 30, 61]: the temperature dependence parameter $\left(c_{1 i}\right)$ and the CPA reduced energy parameter $\left(\Gamma_{i}\right)$ of ions are set to zero; the ions are assumed to be non-associating; the NRTL non-randomness factor and ion-ion interaction parameters are set to zero; the interaction parameters between ions and water are salt-specific, i.e. the cation-water and anion-water interaction parameters are equal.

It is also assumed that the Born radius may be estimated by using the following empirical equations, which were first proposed by Latimer et al. [62] and later supported by molecular simulation [63]

$r_{\text {Born,anion }}=r_{\text {anion }}+0.1 \AA$

$r_{\text {Born, cation }}=r_{\text {cation }}+0.85 \AA$

In Eqs. (14) and (15), $r_{\text {cation }}$ and $r_{\text {anion }}$ are the hard-sphere radii of cation and anion, respectively, which are equal to half of the ion diameters $\left(r_{i}=d_{i} / 2\right) \cdot r_{B o r n, c a t i o n}$ and $r_{B o r n, a n i o n}$ are the Born radii of cation and anion, respectively.

For simple monatomic ions such as $\mathrm{Na}^{+}$and $\mathrm{Cl}^{-}$which can be assumed to be spherical, it is expected that the CPA co-volume parameter can be predicted to fair accuracy using the following equation $[30,46]$

$b=2 / 3 \pi N_{A}\left(2 r_{i}\right)^{3}$

Where $r_{i}$ is the hard-sphere radius of the ion $i$ and $N_{A}$ is the Avogadro constant. 
As mentioned earlier, the $\mathrm{TBA}^{+}$is a relatively large, irregular organic cation with soft alkyl chains, and the negative charge is provided by the nitrogen atom. It is unclear which radius value reflects the physical facts more accurately. In this work, the same $\mathrm{TBA}^{+}$ion radius is used for all three TBAX aqueous solutions. Since the TBAB aqueous solution is the most widely studied system, and the one for which most experimental data is available, the $\mathrm{TBA}^{+}$ion radius is obtained by fitting the TBAB aqueous solution data.

With these assumptions, the estimation procedure is as follows: (1) the ion size of TBA ${ }^{+}$ and HV-NRTL interaction parameters between ions and water are obtained by fitting the mean ionic activity coefficients and osmotic coefficients of TBAB aqueous solutions; (2) fixing the ion size of $\mathrm{TBA}^{+}$, the HV-NRTL interaction parameters between $\mathrm{TBA}^{+}$and water are obtained by fitting the mean ionic activity coefficients and osmotic coefficients simultaneously.

The objective function used for the regression is

$F=\sum\left[\frac{\gamma_{ \pm}^{m}(c a l)-\gamma_{ \pm}^{m}(\exp )}{\gamma_{ \pm}^{m}(\exp )}\right]^{2}+\sum\left[\frac{\Phi(c a l)-\Phi(\exp )}{\Phi(\exp )}\right]^{2}$

Where, $\gamma_{ \pm}^{m}$ represents the mean ionic activity coefficients, and $\Phi$ are the osmotic coefficients, 'cal represents calculated values, and 'exp' are experimental data.

The results are typically listed as percentage average absolute deviations $A A D=\frac{1}{N} \sum_{i}^{N}\left|\frac{y_{i}^{c a l}-y_{i}^{e x p}}{y_{i}^{e x p}}\right| \times 100 \%$

Where, $N$ is the number of data points, $y_{i}^{\text {cal }}$ represents the calculated results of any property, and $y_{i}^{\text {exp }}$ represents the experimental data of a given property.

Mayrath and Wood [35] measured enthalpies of dilution of aqueous solutions of TBAB at 346.15 to $423.65 \mathrm{~K}$, and they used these data to calculate the changes in osmotic coefficients and activity coefficients from $298.15 \mathrm{~K}$ to $373.15 \mathrm{~K}$, which have been used to obtain the temperature dependent interaction parameters

The fitted parameters are presented in Table 3, and the related properties and parameters of water and anions taken from literature $[30,46,64,65,66]$ are given in Tables S1 and 
S2 in the Support Information. The anion radius used in this modeling work is the calculated ionic radius in solution from Marcus [66].

Table 3. Fitted, estimated and fixed e-CPA parameters and the regression performance

\begin{tabular}{|c|c|}
\hline \multicolumn{2}{|c|}{ CPA } \\
\hline$\Gamma[\mathrm{K}]$ & Set to 0 \\
\hline$c_{1}$ & Set to 0 \\
\hline$b\left[\mathrm{~cm}^{3} / \mathrm{mol}\right]$ & $115.2^{*}$ \\
\hline$\beta^{A_{i} B_{j}}$ & Set to 0 \\
\hline$\varepsilon^{A_{i} B_{j}} / R[\mathrm{~K}]$ & Set to 0 \\
\hline \multicolumn{2}{|c|}{ Debye-Hückel and Born terms } \\
\hline$r_{i}[\AA]$ & $2.25\left(\mathrm{TBA}^{+}\right.$, Fit $)$ \\
\hline$r_{\text {Born }, i}[\AA]$ & $3.10^{*}\left(\mathrm{TBA}^{+}\right)$ \\
\hline \multicolumn{2}{|c|}{ Interaction Parameter } \\
\hline & -114.9 (TBAB, Fit) \\
\hline$\Delta U_{i j}^{r e f} / R[\mathrm{~K}]$ & -219.3 (TBAC, Fit) \\
\hline & -450.1 (TBAF, Fit) \\
\hline$T_{\Delta U_{i j}}[\mathrm{~K}]$ & 192.4 (TBAB, Fit) \\
\hline$\omega_{\Delta U_{i j}}[\mathrm{~K}]$ & 137.3 (TBAB, Fit) \\
\hline
\end{tabular}

AAD at $298.15 \mathrm{~K}$

\begin{tabular}{ll}
\hline TBAB aqueous solution $\left(\gamma_{ \pm}^{m} / \Phi\right)$ & $7.2 \% / 5.9 \%(0.0912 \sim 10.0 \mathrm{~mol} / \mathrm{kg})$ \\
TBAC aqueous solution $\left(\gamma_{ \pm}^{m} / \Phi\right)$ & $6.6 \% / 4.5 \%(0.1 \sim 10.0 \mathrm{~mol} / \mathrm{kg})$ \\
TBAF aqueous solution $\left(\gamma_{ \pm}^{m} / \Phi\right)$ & $4.8 \% / 2.6 \%(0.1 \sim 1.6 \mathrm{~mol} / \mathrm{kg})$ \\
\hline
\end{tabular}

* The Born radius $r_{B o r n, i}$ of cation is calculated from ion radius by using Eq. (15), the Born radius of anion is calculated from ion radius by using Eq. (14), the CPA co-volume $b$ is calculated from ion radius by using Eq. (16). 
Figure 3 presents the results of mean ionic activity coefficients and osmotic coefficients of TBAX aqueous solutions. It can be seen that, at the same molality, the order of values of osmotic coefficients and mean ionic activity coefficients are: TBAF > TBAC > TBAB. Combining this with pure component parameters and the parameters of Table 3, we observe that the order of the absolute value of the interaction parameter $\Delta U_{i j}^{r e f}$ follows the opposite order of halide ion size. This can be explained by the fact that the smaller the radius of the halide ion is, the larger interaction with water molecules is expected.

The regressed value of the $\mathrm{TBA}^{+}$radius $r$ is $2.25 \AA$, which is smaller than $3.81 \AA$ [41] (smallest value listed in Table 2), and larger than the value of $N_{3}^{-}(1.46 \AA$ ) [67]. Paricaud [11] reported the molecular radius of $1.927 \AA$ for TBAB, and Ma et al. [16] obtained the ion radius of $1.4555 \AA$ for $\mathrm{TBA}^{+}$. These researchers presented smaller radius of $\mathrm{TBA}^{+}$, one reason being that they did not take the Born term into account which may indicate that they incorporate the hydration effect into the long-range interaction. Moreover, it may indicate that all these electrolyte EOS might have not fully captured the physics of the TBAX aqueous solutions. 


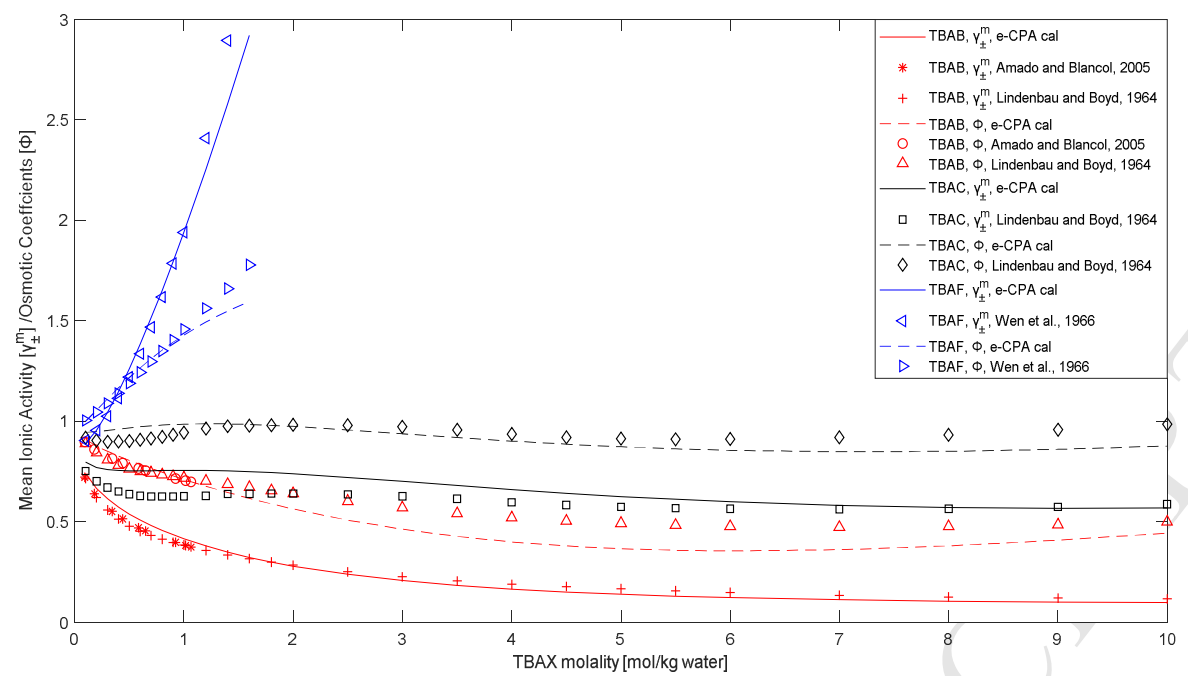

Figure 3. Calculated mean ionic activity coefficients and osmotic coefficients of TBAB, TBAC and TBAF aqueous solutions at $298.15 \mathrm{~K}$ using the e-CPA EOS against experimental data $[33,34,36]$.

\subsection{Modeling of Relative Static Permittivity}

The relative static permittivity plays a very important role in thermodynamic modeling of electrolyte solutions when the primitive approach is employed. The predicted static permittivity from e-CPA is presented in Figure 4 , in which calculation the polarizability of $\mathrm{TBA}^{+}$is $34.70 \times 10^{-40} \mathrm{C} \cdot \mathrm{m}^{2} \cdot \mathrm{V}^{-1}$, taken from Gilkerson and Stewart's work [68]. The dot line represents an empirical equation reported by Buchner et al. [69], in which there are no experimental data reported. It has been stated that ion-pairs [69] and hydrophobic interactions $[69,70]$ exist in TBAX aqueous solution even at moderate concentrations, in which manner, the TBAX could be treated as a 'weak electrolyte' [71]. Both ion-pairs and hydrophobic effects can cause water structure making [72], and strengthen the hydrogen bonding around ions, thus increasing the relative static permittivity. According to Buchner et al. [69] and Kaatze [70], these effects may be responsible for the unusual behavior of the relative static permittivity of TBAB aqueous solution in Figure 4: dielectric saturation and the kinetic depolarization which both contribute to the decrease of the relative static permittivity, and the ion-pairs and hydrophobic hydration contribute to the increase of the relative static permittivity. More discussions are given in the Support Information. 


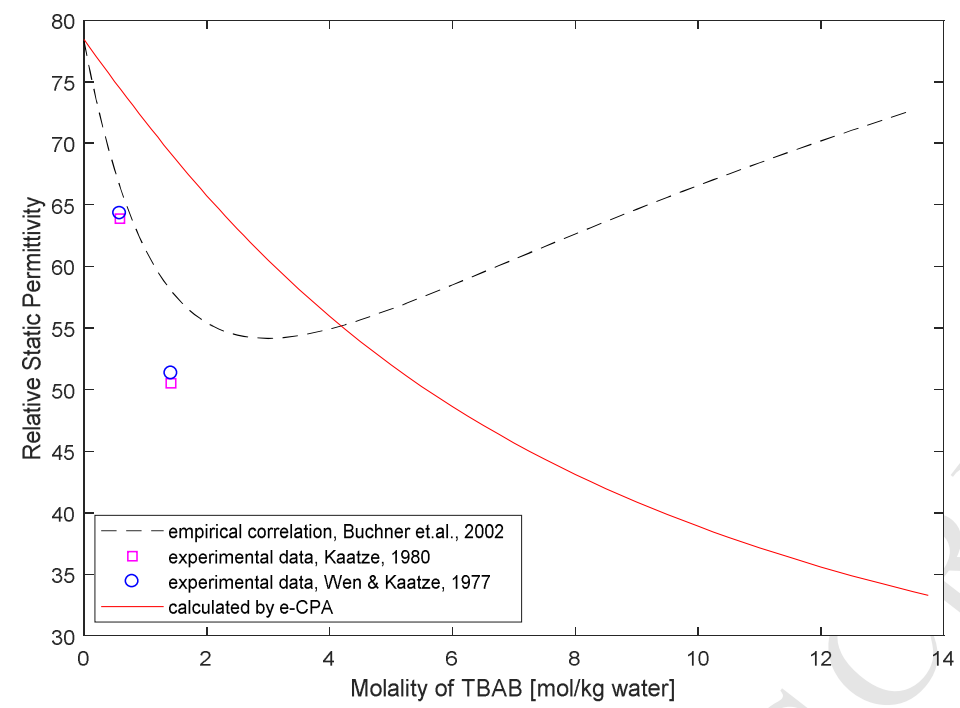

Figure 4. Predicted relative static permittivity of the TBAB aqueous solution binary system at 298.15 K using the e-CPA EOS against the empirical correlation from Buchner et al. [69] and experimental data from Kaatze $[69,73]$.

It can be seen from Figure 4 that the values from e-CPA decrease monotonically with increasing solute molality as is the case for other electrolyte solutions. Under low to medium concentrations, e-CPA gives reasonable relative static permittivity for thermodynamic modeling, as e-CPA ignores the effect of kinetic depolarization which should not be included in thermodynamic modeling. On one hand, it needs to be pointed out that e-CPA does not take dissociation equilibrium into account for the fact that the electrolytes are not fully dissociated [74], so the current version of e-CPA cannot describe the possible ion-pairs and hydrophobic effects in TBAX aqueous solutions. On the other hand, there are very few experimental data of the relative static permittivity published for TBAX aqueous solutions, so more systematic measurements are recommended.

\subsection{Modeling of other Properties}

Volumetric properties are important thermodynamic properties. Unfortunately, only TBAB aqueous solution volumetric data are available $[75,76,77,78]$, and the molality range of experimental data is not as extended as those of the mean ionic activity coefficients and osmotic coefficients shown in Table 1. Few saturation pressure data for aqueous solutions 
are available and only for TBAB aqueous solution [79]. The collected information of other properties is given in the Table S3 in the Support Information.

The liquid density experimental data $[75,76,77,78]$ are only available for the TBAB aqueous solution with the molality lower than $3.1 \mathrm{~mol} / \mathrm{kg}$ water. The modeling results are shown in Figure 5, and it can be seen that e-CPA overestimates the liquid densities of TBAB solution, which may be because the model cannot represent the formation of lowdensity ice-like structures around the large hydrophobic TBA ${ }^{+}$[11].

Maribo-Mogensen et al. [29, 30] introduced a Peneloux volume translation, as shown in Eq. (19), to improve the description of density of salt solutions with e-CPA

$v=v^{E o S}+\sum_{i}^{\text {all ions }} x_{i} C_{i}$

Where $v$ is the molar volume, $v^{E o S}$ is the molar volume calculated from the e-CPA EOS, $x_{i}$ is the mole fraction of ion $i$, and $C_{i}$ is the Peneloux volume correction parameter of ion $i$. As the salt-specific approach is used in this work, the Peneloux parameters of cation and anion are the same.

The solid lines in Figure 5 show that e-CPA can give good agreement with experimental liquid density ( $\mathrm{AAD}=0.2 \%$ ) when using the Peneloux parameter of ions $C_{i}=45.2 \mathrm{~cm}^{3} / \mathrm{mol}$.

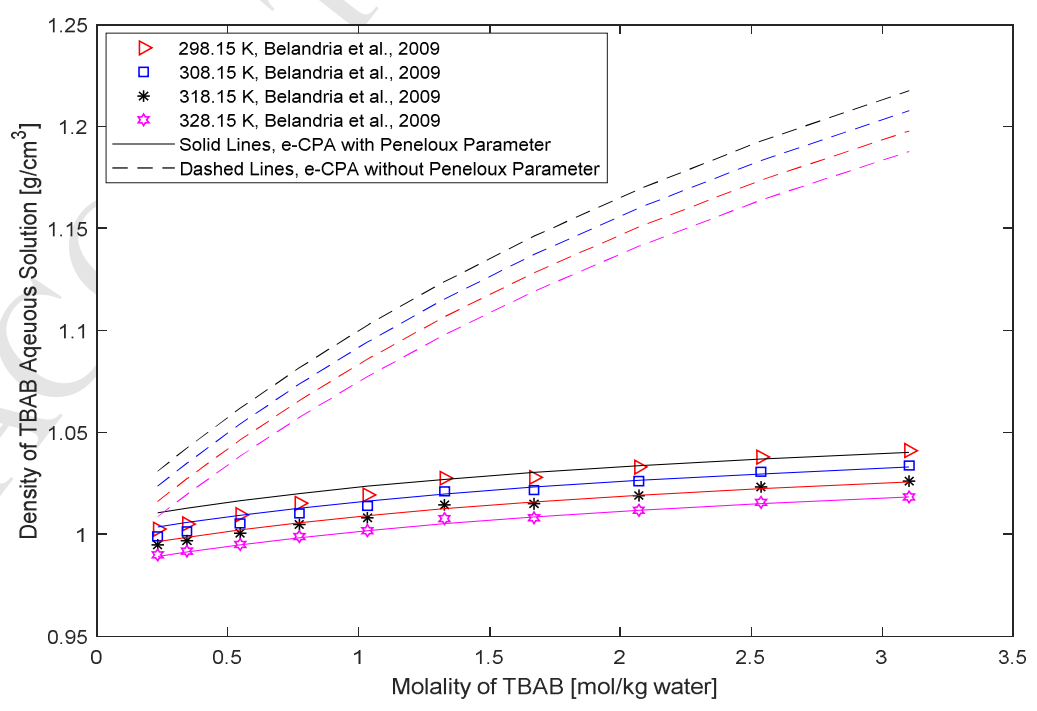


Figure 5. Liquid densities of TBAB solutions at different temperatures from the e-CPA EOS (with parameters in Table 3) with and without using a Peneloux parameter against experimental data from Belandria et al. [76].

In addition to the calculations of activity coefficients, saturation pressure calculations are also important for hydrate modeling. Before calculating the saturation pressure of TBAB aqueous solution, the model was first used to predict the saturation pressure of $\mathrm{NaCl}$ solution under different molality and temperature conditions. The number of experimental data points $[80,81,82,83]$ is 327 , the molality range is $0.5 \sim 7.2 \mathrm{~mol} / \mathrm{kg}$ water, and the temperature range is $273.16 \sim 423.15 \mathrm{~K}$. Excellent results are obtained for $\mathrm{NaCl}$ aqueous solution, as seen in Figure 6 (a). The AAD from the experimental data is $2.0 \%$. It can be assumed that e-CPA can satisfactorily predict saturation pressure for single electrolyte systems.

When e-CPA is used for TBAB aqueous solution, much larger deviations are observed, with $A A D=7.1 \%$ and $5.4 \%$ at the two temperatures, as presented in Figure 6 (b), which also shows the estimated saturation pressure from the experimental osmotic coefficients $P=P_{w}^{\text {sat }} a_{w}$

Where $P$ is the saturation pressure of the system, $P_{w}^{s a t}$ is the saturation pressure of pure water the same temperature, and $a_{w}$ is the activity of water, calculable from the experimental osmotic coefficient.

In this equation, it is assumed that TBAB does not exist in the vapor phase, and it is a strong salt. It can be readily seen that the saturation pressure estimated from experimental osmotic coefficients match the prediction results of e-CPA very well.

In order to further investigate how organic salts perform in terms of saturation pressure, the experimental data of some organic salts aqueous solutions $[84,85,86]$ are collected and analyzed, which are plotted in the Figure $S 3$ in the Support Information. By comparing with saturation pressure data of TBAB aqueous solution, we can see that the saturation pressures of most salt aqueous solutions (including another Tetra-n-butyl ammonium salt $\mathrm{TBANO}_{3}$ aqueous solution) are close to the values of $\mathrm{NaCl}$ aqueous solution in the given 
molality range, while $\mathrm{TBAB}$ aqueous solutions show very different saturation pressure values. Therefore, more systematic measurements for the saturation vapor pressure are needed.

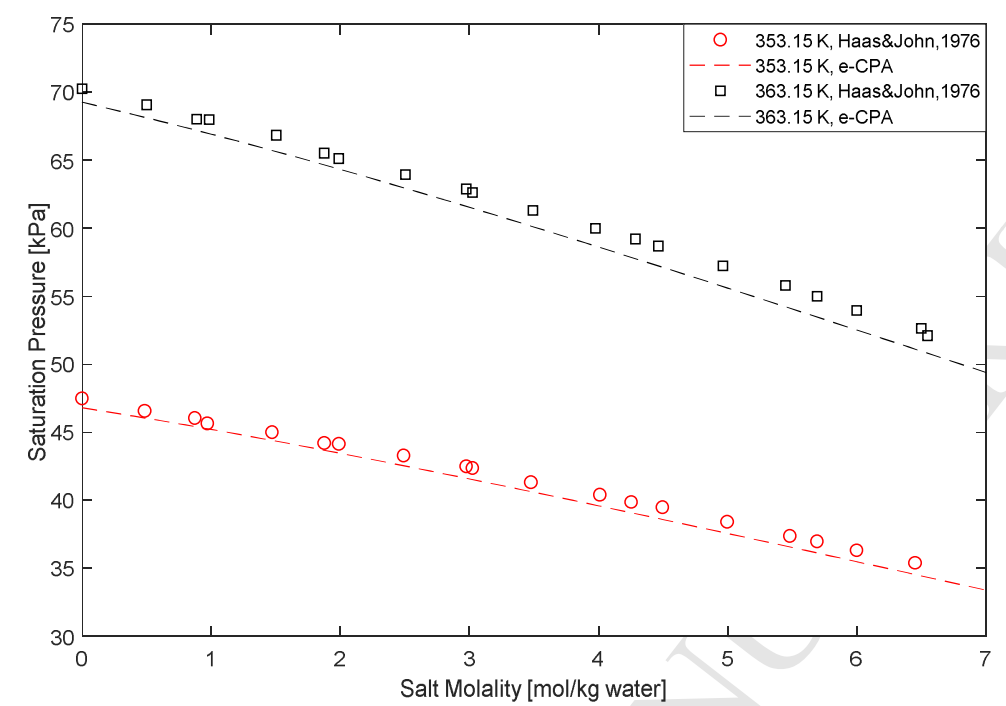

(a)

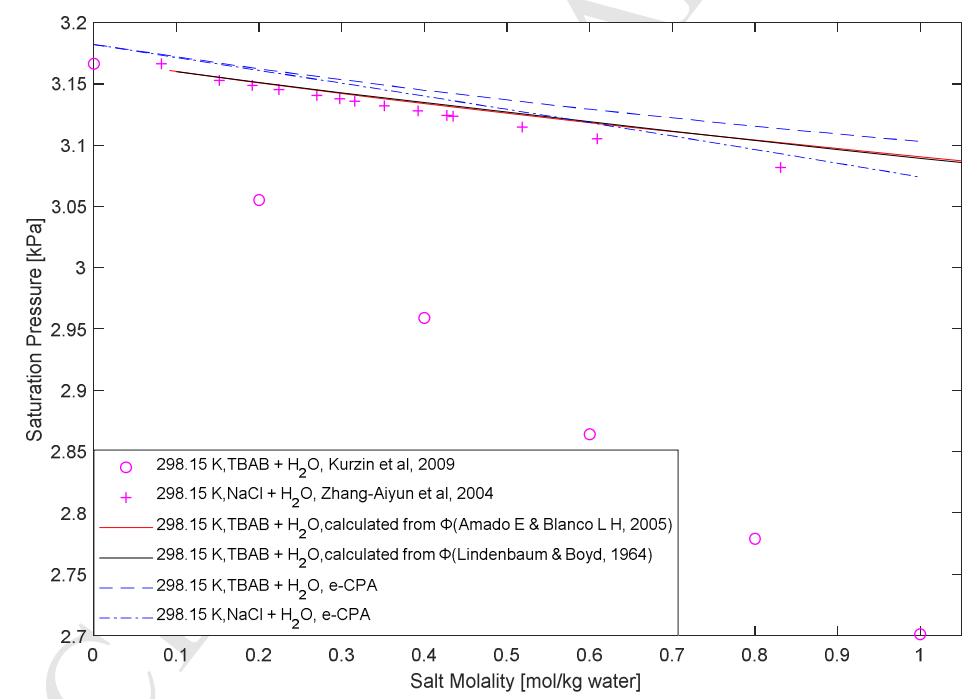

(b)

Figure 6. (a) Predicted saturation pressure of $\mathrm{NaCl}$ aqueous solution for $353.15 \mathrm{~K}$ and $363.15 \mathrm{~K}$ from the e-CPA EOS against experimental data [83]; (b) Saturation pressure of TBAB aqueous solution from e-CPA and experimental osmotic coefficients, and saturation pressure of $\mathrm{NaCl}$ aqueous solution from e-CPA, both at $298.15 \mathrm{~K}$. Experimental data are taken from Kurzin et al. [79], and Zhang et al. [81]. 


\subsection{Discussion}

Thermodynamic modeling for TBAX aqueous solutions has been investigated with different approaches in the literature. Table 4 summarizes the properties studied with different models for the TBAX aqueous solutions in order to present a clear comparison of the different methodologies, and an extensive analysis of parameter estimation in e-CPA has been discussed in the Support Information.

In terms of general modeling approach, SAFT-VRE, MPT, e-CPA and e-NRTL considered TBAX as strong electrolytes in water, and the ion-pairs are not considered. Only AMSANRTL [20] can treat micelle formation because AMSA-NRTL electrolyte model includes a term of ion-pairs contribution. No model takes the possible hydrophobic effect into account.

In terms of density performance, in the $\varphi-\gamma$ approaches, the density of TBAX aqueous solutions was determined using correlation equations. In the $\varphi-\varphi$ approaches, both SAFT-VRE and e-CPA overestimate the experimental densities of TBAB solutions. Paricaud explained that it is because SAFT-VRE cannot represent formation of low-density ice-like structures around the large hydrophobic $\mathrm{TBA}^{+}[11]$. As reported in the section 4.1, the diameter of $\mathrm{TBA}^{+}$in all three models are smaller than the values published in literature (listed in Table 2). Moreover, as shown in Table S4 in the Support Information, the smaller the diameter of $\mathrm{TBA}^{+}$is used, the better density is obtained. These imply that the models might have not captured the essential aspects of physics of TBAX aqueous solution. It is demonstrated in this work that with a Peneloux parameter e-CPA can give a very good agreement with experimental data.

In terms of electrostatic contributions, SAFT-VRE uses a MSA term in Paricaud's work [11], MPT uses a Debye-Hückel term in Ma et al.' work [16], and in this work, e-CPA combines Debye-Hückel and Born terms. Naturally it is the developer's choice to use MSA or Debye-Hückel in an EOS model, as it has been proved that they perform similarly [87]. Different than both SAFT-VRE and MPT, e-CPA explicitly takes ion hydration into account via the Born equation, and the relative static permittivity of electrolyte solution is calculated 
by a theoretical model, which extends the framework developed by Onsager, Kirkwood, and Fröhlich $[88,89,90]$ to associating mixtures. This may increase the complexity of the model but make the model more reasonable.

In principle, SAFT-VRE, MPT, e-CPA and e-NRTL are ion specific by nature, while it is the users' choice when a salt-specific or an ion-specific should be followed, as well as the number of adjustable parameters to be used.

In Paricaud's work [11], the salt-specific approach was used in SAFT-VRE for TBAB, TBAC and TBAF aqueous solutions. For one single salt/single solvent system, there are three adjustable parameters at $298.15 \mathrm{~K}$, one temperature dependent parameter. In the work of Ma et al. [16], the ion-specific approach was used in MPT for TBAB and TBAF aqueous solutions. For one single salt/single solvent system, there are four adjustable parameters at $298.15 \mathrm{~K}$, no temperature dependent parameter.

The salt-specific approach was used in AMSA-NRTL for TBAB aqueous solution. For one single salt/single solvent system, AMSA-NRTL has five adjustable parameters. e-NRTL uses salt-specific approach, it has been applied for TBAB, TBAC and TBAF aqueous solutions. For one single salt/single solvent system, e-NRTL has two adjustable parameters. The temperature dependence of interaction energy parameters was neglected in AMSA-NRTL and e-NRTL for modelling of TBAX aqueous solution systems [21-24].

Unlike the approach using a different ion size for each salt in SAFT-VRE [11], in the presented e-CPA approach, the diameter of $\mathrm{TBA}^{+}$is first fitted to the TBAB data, and then the same value is used for other TBAX systems. In addition to the $\mathrm{TBA}^{+}$diameter, there are one adjustable interaction parameter at $298.15 \mathrm{~K}$, and two temperature dependent interaction parameters.

\section{Conclusions}

This work presents a theoretical study on the thermodynamic modeling for TBAX aqueous solutions by using the e-CPA EOS, which includes Debye-Hückel and Born terms for electrostatic contributions. Several properties of these aqueous solutions as well as 
various modeling approaches have been considered in order to investigate the effect of the number and type of adjustable parameters used.

The thermodynamic modeling of these systems is challenging, among other reasons because the $\mathrm{TBA}^{+}$ion has alkyl chains and low charges, thus exhibiting hydrophobic-like character. There is evidence that the unusual solution behavior of $\mathrm{TBA}^{+}$salts is related to the hydrophobicity of these salts in aqueous solutions.

The e-CPA parameters (ionic size of $\mathrm{TBA}^{+}$, interaction parameters) are estimated from mean ionic activity coefficients and osmotic coefficients. Using the obtained parameters, eCPA was subsequently used to predict the densities of TBAB aqueous solutions and relative static permittivity of TBAX aqueous solutions. It can be concluded that e-CPA can correlate satisfactorily the mean ionic activity coefficients and osmotic coefficients of TBAX aqueous solutions over extensive temperature and concentration ranges. e-CPA with the parameters obtained in this work cannot describe the enhancement of the relative static permittivity due to the ion-pairs and hydrophobic effects. Adding dissociation equilibrium to the model is a potential solution for organic salt solutions where ion-pairs and hydrophobic effects exist. 
Table 4. Properties studies for TBAX aqueous solutions at $298.15 \mathrm{~K}$ *

\begin{tabular}{|c|c|c|c|c|c|c|c|c|c|c|c|c|c|}
\hline \multirow{3}{*}{ Appr. } & \multirow{3}{*}{ Models } & \multirow{2}{*}{\multicolumn{3}{|c|}{$\begin{array}{l}\text { Max molality } \\
{[\mathrm{mol} / \mathrm{kg}]}\end{array}$}} & \multirow{2}{*}{\multicolumn{3}{|c|}{$\begin{array}{l}\text { Adjustable } \\
\text { parameters }\end{array}$}} & \multicolumn{5}{|c|}{ Performance } & \multirow{3}{*}{$\varepsilon_{\mathrm{r}}$ used } \\
\hline & & & & & & & & & $A A D\left(\gamma_{ \pm}^{m} / \Phi\right)$ & & AAD & & \\
\hline & & TBAB & TBAC & TBAF & TBAB & TBAC & TBAF & TBAB & TBAC & TBAF & $\begin{array}{l}\text { density) } \\
\text { (TBAB) }\end{array}$ & (TBAB) & \\
\hline \multirow{3}{*}{$\varphi-\varphi$} & e-CPA & 10.0 & 10.0 & 1.6 & $\begin{aligned} & 1 \text { (TBA }^{+} \\
+1 & \text { (int }\end{aligned}$ & $\begin{array}{l}z e, \text { from } \\
\text { action } p\end{array}$ & $\begin{array}{l}\text { TBAB) } \\
\text { aram) }\end{array}$ & $7.2 \% / 5.9 \%$ & $6.6 \% / 4.5 \%$ & $4.8 \% / 2.6 \%$ & $\begin{array}{l}9.2 \%\left(\text { w/o } C_{i}\right) \\
0.2 \%\left(\text { with } C_{i}\right)\end{array}$ & $\begin{array}{l}7.7 \%(298.15 \mathrm{~K}) \\
5.9 \%(323.15 \mathrm{~K})\end{array}$ & $\begin{array}{c}\text { a theoretical } \\
\text { model }^{\#}\end{array}$ \\
\hline & SAFT-VRE [11] & 10.0 & 10.0 & 1.6 & & 3 & & $3.9 \% / 4.6 \%$ & & - & Overestimate & - & \multirow{2}{*}{$\begin{array}{l}\text { Constant } \\
\text { (equal to } \\
\text { solvent) }\end{array}$} \\
\hline & MPT [16] & - & - & - & 4 & - & 4 & + & - & - & - & - & \\
\hline \multirow{3}{*}{$\varphi-\gamma$} & $\begin{array}{c}\mathrm{EOS}+\mathrm{NRTL}+ \\
\text { correlation } \\
{[25]}\end{array}$ & - & - & - & 2 & - & & - & - & - & \multirow{3}{*}{$\begin{array}{c}\text { Correlation } \\
0.06 \%\end{array}$} & - & - \\
\hline & $\begin{array}{c}\text { EOS + e-NRTL } \\
{[21-23]}\end{array}$ & 27.0 & 15.0 & 1.6 & & 2 & & $3.29 \% /-$ & $4.57 \% /-$ & $1.40 \% /-$ & & - & - \\
\hline & $\begin{array}{c}\text { EOS + AMSA- } \\
\text { NRTL [24] }\end{array}$ & 21.0 & - & - & 5 & & & $\begin{array}{l}1.17 \% / \\
3.54 \%\end{array}$ & - & - & & - & - \\
\hline
\end{tabular}

" e-CPA with parameters in Table 3. For $\varphi-\gamma$ approach, we treat the number of adjustable parameters in activity coefficient model as the total number of adjustable parameters. ${ }^{\#}$ It is composition and volume dependent. 


\section{Acknowledgments}

The authors thank the Department of Chemical and Biochemical Engineering, Technical University of Denmark and the State Scholarship Fund of China Scholarship Council for funding this research.

\section{List of abbreviations/symbols}

List of abbreviations

$\begin{array}{ll}\text { AMSA } & \text { Mean Spherical Approximation for Aqueous Electrolytes includes lonic } \\ & \text { Hydration and Association } \\ \text { CPA } & \text { Cubic-Plus-Association } \\ \text { e-CPA } & \text { electrolyte Cubic-Plus-Association } \\ \text { e-NRTL } & \text { electrolyte Non-Random Two Liquid model } \\ \text { EOS } & \text { Equation of State } \\ \text { MPT } & \text { Modified Patel-Teja } \\ \text { NRTL } & \text { Non-Random Two Liquid model } \\ \text { PR } & \text { Peng-Robinson } \\ \text { SCH } & \text { Semi-Clathrate Hydrate } \\ \text { SAFT-VRE } & \text { Statistical Associating Fluid Theory with Variable Range for Electrolytes } \\ \text { SRK } & \text { Soave-Redlich-Kwong } \\ \text { TB } & \text { Trebble-Bishnoi } \\ \text { TBA }{ }^{+} & \text {Tetra-n-butyl Ammonium Cation } \\ \text { TBP }{ }^{+} & \text {Tetra-n-butyl Phosphonium Cation } \\ \text { TBAX } & \text { Tetra-n-butyl Ammonium Halides } \\ \text { TBAB } & \text { Tetra-n-butyl Ammonium Bromide } \\ \text { TBAC } & \text { Tetra-n-butyl Ammonium Chloride } \\ \text { TBAF } & \text { Tetra-n-butyl Ammonium Fluoride } \\ \text { TBPB } & \text { Tetra-n-butyl Phosphonium Bromide }\end{array}$

List of symbols

a

SRK temperature dependent energy parameter $\left[\frac{\mathrm{Pa} \cdot \mathrm{mol}^{6}}{\mathrm{~mol}^{2}}\right]$ 


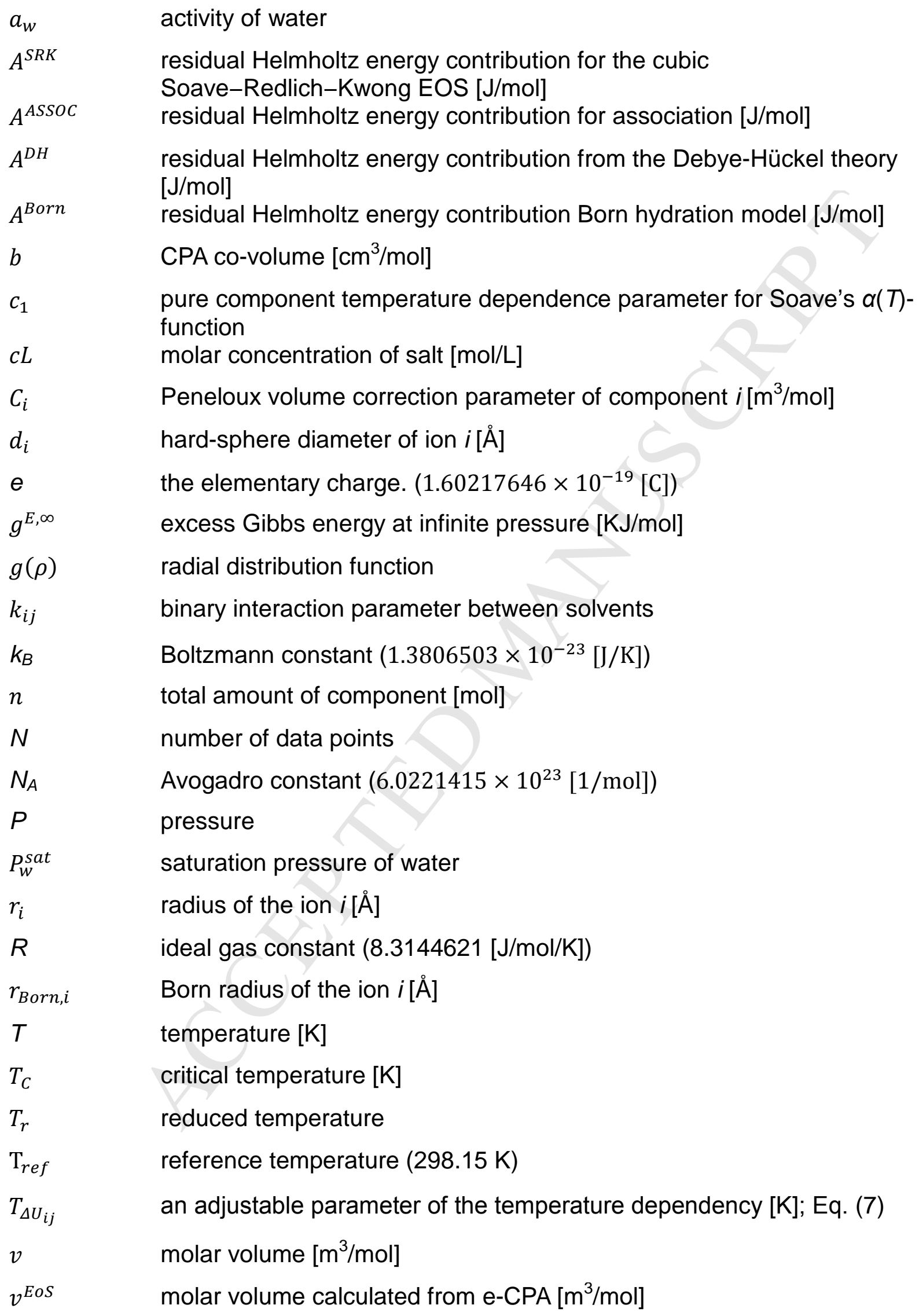




$\begin{array}{ll}V & \text { volume }\left[\mathrm{m}^{3}\right] \\ x_{i} & \text { mole fraction of component } i \\ X_{A i} & \text { fraction of site A on molecule } i \text { that is not bonded to any other site } \\ Z_{i} & \text { charge of ion } i\end{array}$

Greek Symbols

$\alpha_{j i} \quad$ NRTL non-randomness parameter; Eq. (5)

$\beta^{A_{i} B_{j}} \quad$ association volume between site $\mathrm{A}$ on molecule $i$ and site $\mathrm{B}$ on molecule $j$

$\gamma_{ \pm}^{m} \quad$ mean ionic activity coefficient

$\Gamma \quad$ CPA reduced energy parameter $\left(a_{0} / R b\right)[\mathrm{K}]$

$\Delta_{A_{i} B_{j}} \quad$ association strength (equilibrium constant) between site $A$ on molecule $i$ and site B on molecule $j\left[\mathrm{~m}^{3} / \mathrm{mol}\right]$

$\Delta U_{i j} \quad$ Change in interaction energy between like and unlike interactions [J/mol]; Eq. (5)

$\Delta U_{i j}^{r e f} \quad$ binary interaction parameter between ion and water at the reference temperature [J/mol]; Eq. (7)

$\varepsilon^{A_{i} B_{j}} \quad$ association energy between site $\mathrm{A}$ on molecule $i$ and site $\mathrm{B}$ on molecule $j$ [bar.L/mol]

$\varepsilon_{0} \quad$ vacuum permittivity $\left(8.85419 \times 10^{-12}[\mathrm{~F} / \mathrm{m}]\right)$

$\varepsilon_{\mathrm{r}} \quad$ static permittivity relative to vacuum

$\eta \quad$ packing factor; $\eta=b / 4 v$

$\kappa \quad$ inverse Debye length $[1 / \mathrm{m}]$

$\rho \quad$ molar density of fluid $\left[\mathrm{mol} / \mathrm{m}^{3}\right]$

$\Phi \quad$ osmotic coefficient

$\omega_{\Delta U_{i j}} \quad$ linear dependency in interaction energy calculation [K]; Eq. (7) 


\section{References}

[1] S. Fan, S. Li, J. Wang, X. Lang, Y. Wang, Efficient capture of $\mathrm{CO} 2$ from simulated flue gas by formation of TBAB or TBAF semiclathrate hydrates, Energy \& Fuels, 23 (2009) 4202-4208.

[2] J. Deschamps, D. Dalmazzone, Dissociation enthalpies and phase equilibrium for TBAB semi-clathrate hydrates of N2, CO2, N2+ $\mathrm{CO} 2$ and $\mathrm{CH} 4+\mathrm{CO} 2$, Journal of thermal analysis and calorimetry, 98 (2009) 113.

[3] M. Arjmandi, A. Chapoy, B. Tohidi, Equilibrium data of hydrogen, methane, nitrogen, carbon dioxide, and natural gas in semi-clathrate hydrates of tetrabutyl ammonium bromide, Journal of Chemical \& Engineering Data, 52 (2007) 2153-2158.

[4] D. Fowler, W. Loebenstein, D. Pall, C.A. Kraus, Some unusual hydrates of quaternary ammonium salts, Journal of the American Chemical Society, 62 (1940) 1140-1142.

[5] R. McMullan, G.A. Jeffrey, Hydrates of the Tetra n-butyl and Tetra i-amyl Quaternary Ammonium Salts,

The Journal of Chemical Physics, 31 (1959) 1231-1234.

[6] G.A. Jeffrey, Water structure in organic hydrates, Accounts of Chemical Research, 2 (1969) 344-352.

[7] Y.A. Dyadin, K. Udachin, Clathrate polyhydrates of peralkylonium salts and their analogs, Journal of Structural Chemistry, 28 (1987) 394-432.

[8] Y.A. Dyadin, I. Bondaryuk, L. Aladko, Stoichiometry of clathrates, Journal of Structural Chemistry, 36 (1995) 995-1045.

[9] H. Oyama, W. Shimada, T. Ebinuma, Y. Kamata, S. Takeya, T. Uchida, J. Nagao, H. Narita, Phase diagram, latent heat, and specific heat of TBAB semiclathrate hydrate crystals, Fluid Phase Equilibria, 234 (2005) 131-135.

[10] S. Li, S. Fan, J. Wang, X. Lang, Y. Wang, Semiclathrate hydrate phase equilibria for CO2 in the presence of tetra-n-butyl ammonium halide (bromide, chloride, or fluoride), Journal of Chemical \& Engineering Data, 55 (2010) 3212-3215.

[11] P. Paricaud, Modeling the dissociation conditions of salt hydrates and gas semiclathrate hydrates: application to lithium bromide, hydrogen iodide, and tetra-n-butylammonium bromide+ carbon dioxide systems, The Journal of Physical Chemistry B, 115 (2010) 288-299.

[12] A. Fukumoto, P. Paricaud, D. Dalmazzone, W. Bouchafaa, T.T.-S. Ho, W. Fürst, Modeling the dissociation conditions of carbon dioxide+ TBAB, TBAC, TBAF, and TBPB semiclathrate hydrates, Journal of Chemical \& Engineering Data, 59 (2014) 3193-3204.

[13] A. Fukumoto, D. Dalmazzone, P. Paricaud, W. Fürst, Experimental measurements and modeling of the dissociation conditions of tetrabutylammonium chloride semiclathrate hydrates in the presence of hydrogen, Journal of Chemical \& Engineering Data, 60 (2014) 343-350.

[14] A. Fukumoto, L.P.S. Silva, P. Paricaud, D. Dalmazzone, W. Fürst, Modeling of the dissociation conditions of $\mathrm{H} 2+\mathrm{CO} 2$ semiclathrate hydrate formed with TBAB, TBAC, TBAF, TBPB, and TBNO3 salts. Application to CO2 capture from syngas, international journal of hydrogen energy, 40 (2015) 9254-9266.

[15] P. Babu, P. Paricaud, P. Linga, Experimental measurements and modeling of the dissociation conditions of semiclathrate hydrates of tetrabutyl ammonium nitrate and carbon dioxide, Fluid Phase Equilibria, 413 (2016) 80-85.

[16] Q.-L. Ma, J.-L. Qi, G.-J. Chen, C.-Y. Sun, Modeling study on phase equilibria of semiclathrate hydrates of pure gases and gas mixtures in aqueous solutions of TBAB and TBAF, Fluid Phase Equilibria, 430 (2016) 178-187. 
[17] Y.-X. Zuo, T.-M. Guo, Extension of the Patel-Teja equation of state to the prediction of the solubility of natural gas in formation water, Chemical Engineering Science, 46 (1991) 3251-3258.

[18] C.C. Chen, H.I. Britt, J. Boston, L. Evans, Local composition model for excess Gibbs energy of electrolyte systems. Part I: Single solvent, single completely dissociated electrolyte systems, AIChE Journal, 28 (1982) 588-596.

[19] L.S. Belvèze, J.F. Brennecke, M.A. Stadtherr, Modeling of activity coefficients of aqueous solutions of quaternary ammonium salts with the electrolyte-NRTL equation, Industrial \& engineering chemistry research, 43 (2004) 815-825.

[20] J.-P. Simonin, S. Krebs, W. Kunz, Inclusion of ionic hydration and association in the MSA-NRTL model for a description of the thermodynamic properties of aqueous ionic solutions: Application to solutions of associating acids, Industrial \& engineering chemistry research, 45 (2006) 4345-4354.

[21] M. Kwaterski, J.-M. Herri, Thermodynamic modelling of gas semi-clathrate hydrates using the electrolyte NRTL model, 7th International Conference on Gas Hydrates (ICGH 2011), 2011, pp. 437.

[22] J. Verrett, J.-S. Renault-Crispo, P. Servio, Phase equilibria, solubility and modeling study of $\mathrm{CO} / \mathrm{CH} 4+$ tetra-n-butylammonium bromide aqueous semi-clathrate systems, Fluid Phase Equilibria, 388 (2015) 160168.

[23] L.-I. Shi, D.-q. Liang, Thermodynamic model of phase equilibria of tetrabutyl ammonium halide (fluoride, chloride, or bromide) plus methane or carbon dioxide semiclathrate hydrates, Fluid Phase Equilibria, 386 (2015) 149-154.

[24] H. Najibi, K. Momeni, M.T. Sadeghi, A.H. Mohammadi, Experimental measurement and thermodynamic modelling of phase equilibria of semi-clathrate hydrates of ( $\mathrm{CO} 2+$ tetra-n-butyl-ammonium bromide) aqueous solution, The Journal of Chemical Thermodynamics, 87 (2015) 122-128.

[25] A. Eslamimanesh, A.H. Mohammadi, D. Richon, Thermodynamic modeling of phase equilibria of semiclathrate hydrates of $\mathrm{CO} 2, \mathrm{CH} 4$, or $\mathrm{N} 2+$ tetra-n-butylammonium bromide aqueous solution, Chemical Engineering Science, 81 (2012) 319-328.

[26] A. Joshi, P. Mekala, J.S. Sangwai, Modeling phase equilibria of semiclathrate hydrates of $\mathrm{CH} 4, \mathrm{CO} 2$ and N2 in aqueous solution of tetra-n-butyl ammonium bromide, Journal of Natural Gas Chemistry, 21 (2012) 459-465.

[27] Z. Liao, X. Guo, Y. Zhao, Y. Wang, Q. Sun, A. Liu, C. Sun, G. Chen, Experimental and modeling study on phase equilibria of semiclathrate hydrates of tetra-n-butyl ammonium bromide+ $\mathrm{CH} 4, \mathrm{CO} 2, \mathrm{~N} 2$, or gas mixtures, Industrial \& Engineering Chemistry Research, 52 (2013) 18440-18446.

[28] Z.-x. Liao, X.-q. Guo, Q. Li, Q. Sun, J. Li, L.-y. Yang, A.-x. Liu, G.-j. Chen, J.Y. Zuo, Experimental and modeling study on the phase equilibria for hydrates of gas mixtures in TBAB solution, Chemical Engineering Science, 137 (2015) 656-664.

[29] B. Maribo-Mogensen, K. Thomsen, G.M. Kontogeorgis, An electrolyte CPA equation of state for mixed solvent electrolytes, AIChE Journal, 61 (2015) 2933-2950.

[30] B. Maribo-Mogensen, Development of an Electrolyte CPA Equation of state for Applications in the Petroleum and Chemical Industries, DTU Chemical Engineering, Department of Chemical and Biochemical Engineering2014.

[31] N. PubChem, Pubchem compound. NCBI, National Center for Biotechnology Information. http://pubchem. ncbi. nlm. nih. gov. 
[32] Y. Marcus, Tetraalkylammonium ions in aqueous and non-aqueous solutions, Journal of Solution Chemistry, 37 (2008) 1071.

[33] S. Lindenbaum, G. Boyd, Osmotic and activity coefficients for the symmetrical tetraalkyl ammonium halides in aqueous solution at 25, The Journal of Physical Chemistry, 68 (1964) 911-917.

[34] E. Amado, L.H. Blanco, Isopiestic determination of the osmotic and activity coefficients of dilute aqueous solutions of symmetrical and unsymmetrical quaternary ammonium bromides with a new isopiestic cell at 298.15 K, Fluid phase equilibria, 233 (2005) 230-233.

[35] J.E. Mayrath, R.H. Wood, Enthalpies of dilution of aqueous solutions of two hydrophobic solutes: tbutanol and tetra-n-butylammonium bromide, at 348.15 to $423.65 \mathrm{~K}$, The Journal of Chemical Thermodynamics, 15 (1983) 625-632.

[36] W.Y. Wen, S. Saito, C.m. Lee, Activity and osmotic coefficients of four symmetrical tetraalkylammonium fluorides in aqueous solutions at 25, The Journal of Physical Chemistry, 70 (1966) 1244-1248.

[37] K. Pitzer, The Nature of the Chemical Bond and the Structure of Molecules and Crystals: An Introduction to Modern Structural Chemistry, Journal of the American Chemical Society, 82 (1960) 4121-4121.

[38] R.A. Robinson, R.H. Stokes, Electrolyte solutions, Courier Corporation2002.

[39] C. Treiner, P. Tzias, M. Chemla, G.M. Poltoratskii, Solvation of tetrabutylammonium bromide in water+ acetonitrile mixtures at $298.15 \mathrm{~K}$ from vapour pressure measurements of dilute solutions, Journal of the Chemical Society, Faraday Transactions 1: Physical Chemistry in Condensed Phases, 72 (1976) 2007-2015.

[40] T. Osakai, A. Ogata, K. Ebina, Hydration of ions in organic solvent and its significance in the Gibbs energy of ion transfer between two immiscible liquids, The Journal of Physical Chemistry B, 101 (1997) 8341-8348.

[41] W. Masterton, D. Bolocofsky, T.P. Lee, Ionic radii from scaled particle theory of the salt effect, The Journal of Physical Chemistry, 75 (1971) 2809-2815.

[42] E. Nightingale Jr, Phenomenological theory of ion solvation. Effective radii of hydrated ions, The Journal of Physical Chemistry, 63 (1959) 1381-1387.

[43] D.S. Berns, R.M. Fuoss, Electrolyte-Solvent Interaction. IX. Tetra-alkylammonium Tetraphenylborides in Acetonitrile-Carbon Tetrachloride Mixtures at $25^{\circ}$, Journal of the American Chemical Society, 82 (1960) 55855588.

[44] J. Coetzee, G. Cunningham, Evaluation of single ion conductivities in acetonitrile, nitromethane, and nitrobenzene using tetraisoamylammonium tetraisoamylboride as reference electrolyte, Journal of the American Chemical Society, 87 (1965) 2529-2534.

[45] Y.H. Zhao, M.H. Abraham, A.M. Zissimos, Determination of McGowan volumes for ions and correlation with van der Waals volumes, Journal of chemical information and computer sciences, 43 (2003) 1848-1854.

[46] G.M. Kontogeorgis, E.C. Voutsas, I.V. Yakoumis, D.P. Tassios, An equation of state for associating fluids, Industrial \& engineering chemistry research, 35 (1996) 4310-4318.

[47] P. Debye, E. Huckel, The interionic attraction theory of deviations from ideal behavior in solution, $Z$. Phys, 24 (1923) 185.

[48] M. Born, Volumen und hydratationswärme der ionen, Zeitschrift für Physik, 1 (1920) 45-48.

[49] E. Hückel, Zur Theorie der Elektrolyte, Ergebnisse der exakten naturwissenschaften, Springer1924, pp. 199-276.

[50] G. Soave, Equilibrium constants from a modified Redlich-Kwong equation of state, Chemical Engineering Science, 27 (1972) 1197-1203. 
[51] M.P. Breil, G.M. Kontogeorgis, P.K. Behrens, M.L. Michelsen, Modeling of the thermodynamics of the acetic acid-water mixture using the cubic-plus-association equation of state, Industrial \& Engineering Chemistry Research, 50 (2011) 5795-5805.

[52] W.G. Chapman, K.E. Gubbins, G. Jackson, M. Radosz, SAFT: Equation-of-state solution model for associating fluids, Fluid Phase Equilibria, 52 (1989) 31-38.

[53] M. Wertheim, Fluids with highly directional attractive forces. I. Statistical thermodynamics, Journal of statistical physics, 35 (1984) 19-34.

[54] M. Wertheim, Fluids with highly directional attractive forces. II. Thermodynamic perturbation theory and integral equations, Journal of statistical physics, 35 (1984) 35-47.

[55] M. Wertheim, Fluids with highly directional attractive forces. III. Multiple attraction sites, Journal of statistical physics, 42 (1986) 459-476.

[56] M. Wertheim, Fluids with highly directional attractive forces. IV. Equilibrium polymerization, Journal of statistical physics, 42 (1986) 477-492.

[57] M.L. Michelsen, E.M. Hendriks, Physical properties from association models, Fluid phase equilibria, 180 (2001) 165-174.

[58] J.A. Myers, S.I. Sandler, R.H. Wood, An equation of state for electrolyte solutions covering wide ranges of temperature, pressure, and composition, Industrial \& engineering chemistry research, 41 (2002) 32823297.

[59] M. Hartmann, M. Hartmann, 25 Jahre Kaiser Wilhelm-Gesellschaft zur Förderung der Wissenschaften: Zweiter Band Die Naturwissenschaften, (1936).

[60] J.-L. Burgot, The notion of activity in chemistry, Springer2017.

[61] B. Maribo-Mogensen, G.M. Kontogeorgis, K. Thomsen, Modeling of dielectric properties of aqueous salt solutions with an equation of state, The Journal of Physical Chemistry B, 117 (2013) 10523-10533.

[62] W.M. Latimer, K.S. Pitzer, C.M. Slansky, The free energy of hydration of gaseous ions, and the absolute potential of the normal calomel electrode, Molecular Structure And Statistical Thermodynamics: Selected Papers of Kenneth S Pitzer, World Scientific1993, pp. 485-489.

[63] S. Rajamani, T. Ghosh, S. Garde, Size dependent ion hydration, its asymmetry, and convergence to macroscopic behavior, The Journal of chemical physics, 120 (2004) 4457-4466.

[64] G.M. Kontogeorgis, G.K. Folas, Thermodynamic models for industrial applications: from classical and advanced mixing rules to association theories, John Wiley \& Sons2009.

[65] W.M. Haynes, CRC handbook of chemistry and physics, CRC press2014.

[66] Y. Marcus, lonic radii in aqueous solutions, Chemical Reviews, 88 (1988) 1475-1498.

[67] R.D. Shannon, Revised effective ionic radii and systematic studies of interatomic distances in halides and chalcogenides, Acta crystallographica section A: crystal physics, diffraction, theoretical and general crystallography, 32 (1976) 751-767.

[68] W. Gilkerson, J. Stewart, Polarizabilities and molar volumes of a number of salts in several solvents at 25․ The Journal of Physical Chemistry, 65 (1961) 1465-1466.

[69] R. Buchner, C. Hölzl, J. Stauber, J. Barthel, Dielectric spectroscopy of ion-pairing and hydration in aqueous tetra-n-alkylammonium halide solutions, Physical Chemistry Chemical Physics, 4 (2002) 21692179.

[70] U. Kaatze, Kinetic depolarization in aqueous solutions of alkylammonium bromides, Berichte der Bunsengesellschaft für physikalische Chemie, 84 (1980) 1195-1197. 
[71] C. Held, G. Sadowski, Modeling aqueous electrolyte solutions. Part 2. Weak electrolytes, Fluid Phase Equilibria, 279 (2009) 141-148.

[72] R.W. Gurney, Ionic processes in solution, McGraw-Hill, 1953.

[73] U. Kaatze, Complex permittivity of water as a function of frequency and temperature, Journal of Chemical and Engineering Data, 34 (1989) 371-374.

[74] R. Cole, J. Berberian, S. Mashimo, G. Chryssikos, A. Burns, E. Tombari, Time domain reflection methods for dielectric measurements to $10 \mathrm{GHz}$, Journal of applied physics, 66 (1989) 793-802.

[75] B. Sinha, B.K. Sarkar, M.N. Roy, Apparent molar volumes and viscosity B-coefficients of nicotinamide in aqueous tetrabutylammonium bromide solutions at $\mathrm{T}=(298.15,308.15$, and 318.15$) \mathrm{K}$, The Journal of Chemical Thermodynamics, 40 (2008) 394-400.

[76] V. Belandria, A.H. Mohammadi, D. Richon, Volumetric properties of the (tetrahydrofuran+ water) and (tetra-n-butyl ammonium bromide+ water) systems: Experimental measurements and correlations, The Journal of Chemical Thermodynamics, 41 (2009) 1382-1386.

[77] M. Roy, R. Das, A. Bhattacharjee, Apparent molar volume, viscosity B-coefficient, and adiabatic compressibility of tetrabutylammonium bromide in aqueous ascorbic acid solutions at $T=298.15,308.15$, and 318.15 K, Russian Journal of Physical Chemistry A, 84 (2010) 2201-2210.

[78] H. Hooshyar, B. Khezri, Volumetric Properties of Tetra-n-butyl ammonium bromide in Aqueous Solutions of Magnesium sulphate in the Temperature Range 298.15 to $318.15 \mathrm{~K}$ and under the Atmospheric Pressure, Physics and Chemistry of Liquids, 54 (2016) 663-679.

[79] A.V. Kurzin, A.N. Evdokimov, V.B. Antipina, O.S. Pavlova, Vapor Pressures for the Acetonitrile+ Tetrabutylammonium Bromide, Water+ Tetrabutylammonium Bromide, and Acetonitrile+ Water+ Tetrabutylammonium Bromide Systems, Journal of Chemical \& Engineering Data, 54 (2008) 1049-1051.

[80] A. Apelblat, E. Korin, The vapour pressures of saturated aqueous solutions of sodium chloride, sodium bromide, sodium nitrate, sodium nitrite, potassium iodate, and rubidium chloride at temperatures from $227 \mathrm{~K}$ to $323 \mathrm{~K}$, The Journal of Chemical Thermodynamics, 30 (1998) 59-71.

[81] A. Zhang, Y. Yao, P. Song, Isopiestic determination of vapor pressures and osmotic coefficients and the ion-interaction model for Li2B4O7-H2O system at $298.15 \mathrm{~K}$, CHEMICAL JOURNAL OF CHINESE UNIVERSITIES-CHINESE, 25 (2004) 1934-1936.

[82] B. Fabuss, A. Korosi, Vapor pressures of binary aqueous solutions of $\mathrm{NaCl}, \mathrm{KCl}, \mathrm{Na2SO} 4$ and $\mathrm{MgSO} 4$ at concentrations and temperatures of interest in desalination processes, Desalination, 1 (1966) 139-148.

[83] J.L. Haas Jr, Thermodynamics properties of the coexisting phases and thermochemical properties of the $\mathrm{NaCl}$ component in boiling NaCl solutions, US, Geol. Surv., Bull.;(United States), 1421 (1976).

[84] A.V. Kurzin, A.N. Evdokimov, V.B. Antipina, O.S. Pavlova, V.E. Gusev, Vapor Pressures for 1, 4Dioxane+ Tetrabutylammonium Nitrate, Water+ Tetrabutylammonium Nitrate, and 1, 4-Dioxane+ Water+ Tetrabutylammonium Nitrate, Journal of Chemical \& Engineering Data, 53 (2007) 207-210.

[85] L.-s. Lee, C.-c. Lee, Vapor pressures and enthalpies of vaporization of aqueous solutions of benzyltrimethylammonium chloride, benzyltriethylammonium chloride, and benzltributylammonium chloride, Journal of Chemical \& Engineering Data, 43 (1998) 17-20.

[86] L.-s. Lee, C.-c. Lee, Vapor pressures and enthalpies of vaporization of aqueous solutions of triethylammonium chloride, 2-hydroxyethylammonium chloride, and tris (hydroxymethyl) aminomethane hydrochloride, Journal of Chemical \& Engineering Data, 43 (1998) 469-472.

[87] B. Maribo-Mogensen, G.M. Kontogeorgis, K. Thomsen, Comparison of the Debye-Hückel and the Mean Spherical Approximation Theories for Electrolyte Solutions. Ind. Eng. Chem. Res. 51 (2012) 5353- 5363. 
[88] L. Onsager, Electric moments of molecules in liquids, Journal of the American Chemical Society, 58 (1936) 1486-1493.

[89] J.G. Kirkwood, The dielectric polarization of polar liquids, The Journal of Chemical Physics, 7 (1939) 911-919.

[90] H. Fröhlich, Theory of dielectrics: dielectric constant and dielectric loss, Clarendon Press 1958. 